\title{
Effect of 4-aminoantipyrine on gastric compliance and liquid emptying in rats
}

A.M. Vinagre ${ }^{2}$

and E.F. Collares ${ }^{1,2,3}$
${ }^{1}$ Departamento de Pediatria, ${ }^{2}$ Núcleo de Medicina e Cirurgia Experimental, ${ }^{3}$ Centro de Investigação em Pediatria, Faculdade de Ciências Médicas, Universidade Estadual de Campinas, Campinas, SP, Brasil
Correspondence

E.F. Collares

Departamento de Pediatria

Faculdade de Ciências Médicas UNICAMP

13083-970 Campinas, SP

Brasil

Fax: +55-19-3521-7322

E-mail: efcollares@hotmail.com

Publication supported by FAPESP.

$\ldots \ldots \ldots \ldots \ldots \ldots$

Received September 29, 2006 Accepted May 9, 2007

\begin{abstract}
Dipyrone (Dp) delays gastric emptying (GE) in rats. There is no information about whether 4-aminoantipyrine (AA), one of its metabolites, has the same effect. The objectives of the present study were to assess the effects of AA and Dp on GE when administered intravenously (iv) and intracerebroventricularly (icv) $(240 \mu \mathrm{mol} / \mathrm{kg}$ and 4 $\mu \mathrm{mol} /$ animal, respectively) and on gastric compliance when administered iv $(240 \mu \mathrm{mol} / \mathrm{kg})$. GE was determined in male Wistar rats weighing 250-300 g (5-10 per group) after $i c v$ or $i v$ injection of the drug by measuring percent gastric retention (GR) of a saline meal labeled with phenol red $10 \mathrm{~min}$ after administration by gavage. Gastric compliance was estimated in anesthetized rats (10-11 per group), with the construction of volume-pressure curves during intragastric infusion of a saline meal. Compliance was significantly greater in animals receiving Dp (mean $\pm \mathrm{SEM}=0.26 \pm 0.009 \mathrm{~mL} / \mathrm{mmHg})$ and AA $(0.24$ $\pm 0.012 \mathrm{~mL} / \mathrm{mmHg})$ than in controls $(0.19 \pm 0.009 \mathrm{~mL} / \mathrm{mmHg})$. AA and Dp administered $i v$ significantly increased GR (64.4 \pm 2.5 and $54.3 \pm 3.8 \%$, respectively) compared to control (34 $\pm 2.2 \%)$, a phenomenon observed only with Dp after icv administration. Subdiaphragmatic vagotomy reduced the effect of AA $(\mathrm{GR}=31.4 \pm 1.5 \%)$ compared to sham-treated animals. Baclofen, a $\mathrm{GABA}_{\mathrm{B}}$ receptor agonist, administered $i c v$ significantly reduced the effect of $\mathrm{AA}(\mathrm{GR}=$ $28.1 \pm 1.3 \%$ ). We conclude that Dp and AA increased gastric compliance and AA delayed GE, with the participation of the vagus nerve, through a pathway that does not involve a direct action of the drug on the central nervous system.
\end{abstract}

Key words

- Gastric emptying

- Gastric compliance

- 4-Aminoantipyrine

- Dipyrone

- Vagus nerve

\section{Introduction}

Dipyrone (Dp), a phenylpyrazolone derivative, administered intravenously (iv) and intracerebroventricularly (icv) to rats, delays the gastric emptying (GE) of a liquid meal. When the drug was administered $i v$ the phenomenon was abolished by vagotomy and by electrolytic lesion of the paraventricular nucleus of the hypothalamus (1). Furthermore, it was demonstrated that this effect is blocked by $i c v$ injection of baclofen (bac), a $\mathrm{GABA}_{\mathrm{B}}$ receptor agonist (2).

$\mathrm{GE}$ is the process of gastric content transfer to the small intestine caused by the coordinated motor activity of the stomach, pylorus and duodenum (3). In situations in which there is an alteration of GE, the par- 
ticipation of the stomach in the process can be inferred by the in vivo determination of volume and of gastric compliance as indicators of gastric tonus (4). Gastric tonus reflects variations in the tonic contractions of the proximal area of the stomach, which is responsible for accommodation of the food bolus. The tonus of this region is the result of the balance of stimulatory (increasing) and inhibitory (reducing) activities, with regulation mostly occurring via the vagus nerve. In general, the reduction of tonus is accompanied by a slower GE of fluid (5). On the other hand, the mechanical increase of gastric tonus by fundoplication in rats was accompanied by an increased liquid GE (4). It is possible that the delayed GE determined by $\mathrm{Dp}$ is due to a reduction of gastric tonus.

Dp (sodium salt of antipyrinyl-methylaminomethane-sufonic acid) is a pro-drug that is rapidly hydrolyzed by the gastric juice when administered by the oral route, forming 4-methylaminoantipyrine and being absorbed in this form $(6,7)$. 4-Methylaminoantipyrine is directly demethylated, mostly in the liver, to 4-aminoantipyrine (AA), with the later generation of other metabolites. Cytochrome P450 metabolic isoenzymes participate in this process $(7,8)$. The pharmacological properties of Dp are attributed to its active metabolites 4-methylaminoantipyrine and AA $(6,7)$.

There are no literature reports about the effect of Dp metabolites on GE although it has been demonstrated that phenylpyrazolone derivatives induce delayed GE $(9,10)$. In a previous study by our group, we demonstrated that the $i v$ administration of AA reduces the GE of liquid in rats (11).

On this basis, the objectives of the present study carried out on rats were: 1) to compare the effect of Dp and AA administered $i v$ and $i c v$ on GE, 2) to assess the $i v$ effect of the two drugs on the stomach compliance of anesthetized rats, 3) to determine the effect of $i v$ administration of AA on GE in terms of doseresponse and time-response, and 4) to assess the participation of the vagus nerve and of $\mathrm{GABA}_{\mathrm{B}}$ receptors of the central nervous system (CNS) in the effect of $i v$ administration of AA on GE.

\section{Material and Methods}

Male Wistar rats weighing 250-300 g were used. The experimental protocols applied in the present study obeyed the recommendations of the Brazilian College of Animal Experimentation (COBEA). Before being submitted to the surgical procedures for vagotomy or for the implantation of a cannula into the lateral ventricle of the brain, the animals were sedated with an ip injection of thiopental, $75 \mathrm{mg} / \mathrm{kg}$. After the procedures or after entry in the study the animals were kept in individual cages with free access to water and ration. For the study of gastric compliance, the animal was anesthetized with a mixture of $85 \mathrm{mg} / \mathrm{kg}$ ketamine $+10 \mathrm{mg} / \mathrm{kg}$ xylazine administered ip.

Dp (Sigma, St. Louis, MO, USA), AA (Sigma) and bac (Sigma) were diluted with sterile physiological saline as a vehicle at the time of the study. The doses, in $\mu \mathrm{mol}$, applied $i v$ and $i c v$ were established on the basis of previous studies with Dp (1,2). GE and stomach compliance were determined after a 24-h fast, although the animals continued to receive water ad libitum up to $30 \mathrm{~min}$ before the studies.

In all the studies described below, except for the time-response effect, GE was assessed in each animal $10 \mathrm{~min}$ after the $i v$ or $i c v$ administration of the drug or vehicle. For the comparison of the effect of $i v$ administration on GE, $240 \mu \mathrm{mol} / \mathrm{kg}$ Dp or AA (80 and $48.77 \mathrm{mg} / \mathrm{kg}$, respectively) or vehicle (control) were administered through a caudal vein. In the study of the icv effect, a stainless steel cannula (22 G) was implanted into the right lateral ventricle of each animal eight days before the experiment using previously established coordinates (1). An internal microinjection cannula $(28 \mathrm{G})$ con- 
nected by polyethylene tubing to a $25-\mu \mathrm{L}$ Hamilton syringe was used for $i c v$ injection. A $10-\mu \mathrm{L}$ volume of vehicle (control) or $\mathrm{Dp}$ solution $(4 \mu \mathrm{mol}=1333.2 \mu \mathrm{g})$ or AA solution $(4 \mu \mathrm{mol}=812.8 \mu \mathrm{g})$ was used.

In the dose-response study, $30(6.09 \mathrm{mg} /$ $\mathrm{kg}), 60(12.19 \mathrm{mg} / \mathrm{kg}), 120(24.38 \mathrm{mg} / \mathrm{kg})$, and $240 \mu \mathrm{mol} / \mathrm{kg}(48.77 \mathrm{mg} / \mathrm{kg})$ AA were administered $i v$. Control animals received vehicle by the same route.

For the evaluation of the participation of the vagus nerve, the rats were submitted to subdiaphragmatic section of the ventral and dorsal branches of the vagus ( $\mathrm{VgX}$ group) two weeks before the experiment. The sham group consisted of rats submitted to surgery without sectioning of the vagus. Each of these groups was divided into two groups receiving vehicle (control) and $\mathrm{AA}$ at the dose of $240 \mu \mathrm{mol} / \mathrm{kg}(48.77 \mathrm{mg} / \mathrm{kg}) i v$, respectively.

The participation of $\mathrm{GABA}_{\mathrm{B}}$ receptors in the CNS in the effect of AA on GE was assessed by using icv injection of $10 \mu \mathrm{L}$ vehicle (bac0), or of a solution containing $2 \mu \mathrm{g}$ baclofen (bac2), followed by $i v$ vehicle (control), or an AA solution of $240 \mu \mathrm{mol} / \mathrm{kg}$. For the study of the time-response effect, 240 $\mu \mathrm{mol} / \mathrm{kg}(48.77 \mathrm{mg} / \mathrm{kg})$ AA or vehicle were injected $i v$ and GE was determined 10, 30, 60, 120 , and $240 \mathrm{~min}$ after administration.

GE was evaluated indirectly in awake animals by determining percent gastric retention (GR) of $2 \mathrm{~mL} / \mathrm{kg}$ of a saline test meal labeled with phenol red at the concentration of $60 \mu \mathrm{g} /$ $\mathrm{mL}, 10 \mathrm{~min}$ after administration by gavage using a standardized technique (12). The absorbance of the dye was read with a spectrophotometer at 560-nm wavelength.

Compliance was measured by the technique described by Bustorff-Silva et al. (4). After a 24-h fast, the animals were anesthetized and submitted to tracheotomy, abdominal incision, lavage of the stomach after pylorus ligation, and fixation in the distal esophagus of an orogastric polyethylene tube (2-mm inner diameter and $25 \mathrm{~cm}$ in length) filled with saline and connected through a three-way stop cock to an infusion pump (model LF 2001; Lifemed, São Paulo, SP, Brazil) and to a monitor for pressure recording (Biomonitor 7; BESE, São Paulo, SP, Brazil). Thirty minutes after these procedures, each animal received an $i v$ infusion through the external jugular of vehicle (control group), or of Dp or AA at the dose of 240 $\mu \mathrm{mol} / \mathrm{kg}$. Ten minutes after $i v$ application, saline solution at $37^{\circ} \mathrm{C}$ was infused into the stomach at the rate of $2 \mathrm{~mL} 100 \mathrm{~g}^{\text {weight }}{ }^{-1}$ $\mathrm{min}^{-1}$ intermittently every $20 \mathrm{~s}$ at 1 -min intervals. The infusion was stopped every $20 \mathrm{~s}$ (1/3 of the volume) and the system was equilibrated for $50 \mathrm{~s}$, with recording of intragastric pressure (IGP). IGP values corresponding to $1 / 3$ and $2 / 3$ of the volume and to the total volume were recorded and the procedure was repeated two more times at 30min intervals. The results for each animal corresponded to the mean of the three IGP measurements at each point. Volume-pressure curves were constructed to estimate gastric compliance, which was calculated by the following formula: compliance $(\mathrm{mL} /$ $\mathrm{mmHg})=\mathrm{V}_{1}-\mathrm{V}_{0} / \mathrm{P}_{1}-\mathrm{P}_{0}$, where $\mathrm{V}_{0}=$ initial volume and $\mathrm{V}_{1}=$ final volume, $\mathrm{P}_{0}=$ initial IGP and $\mathrm{P}_{1}=$ final IGP

At the end of the experiments all animals were sacrificed and $10 \mu \mathrm{L} 1 \%$ Evans blue solution was injected by the same route in those that had received icv injection. The brain was removed and fixed in $10 \%$ formalin for $24 \mathrm{~h}$. After fixation, coronal sections of the brain were obtained and $i c v$ injection was confirmed when the dye was seen in the 4th ventricle.

Data are reported as mean \pm SEM and were analyzed statistically by ANOVA followed by the Tukey test, when necessary, for pair comparisons. The $\alpha$ value was set at 5\%.

\section{Results}

Data regarding the $i v$ effect of $\mathrm{Dp}$ and AA are presented in Figure 1A. Dp and AA 
Figure 1. Gastric retention of a saline test meal 10 min after administration to rats by gavage. $A$, Ten minutes before the evaluation of gastric retention, the animals received iv administration of vehicle (C), $240 \mu \mathrm{mol} / \mathrm{kg}$ dipyrone $(\mathrm{Dp}, 80 \mathrm{mg} / \mathrm{kg})$ or 4 aminoantipyrine (AA, $48.8 \mathrm{mg} /$ $\mathrm{kg}) . B, A$ metal cannula was implanted into the right lateral ventricle of all rats 8 days before the experiment. The animals received icv administration of 10 $\mu \mathrm{L}$ vehicle (C) or an equal vol$\mu \mathrm{mol}(1.33 \mathrm{mg}$ ) Dp or $4 \mu \mathrm{mol}$ $(813 \mu \mathrm{g})$ AA. Gastric retention was evaluated $10 \mathrm{~min}$ after the icv injections. Data are reported as mean \pm SEM for 10 animals per group. ${ }^{*} \mathrm{P}<0.05$ compared to control (Tukey test). ume of a solution containing 4

caused significantly greater GR compared to control. The increase in GR was more marked in the AA group (mean \pm SEM, $64.4 \pm 2.5 \%$ ) but was not significant compared to Dp (54.3 $\pm 3.8 \%)$. A comparative evaluation of the $i c v$ effect of $\mathrm{Dp}$ and $\mathrm{AA}$ is presented in Figure 1B. A significant increase in GR was observed in the Dp group compared to control, a fact that was not observed after the admin-

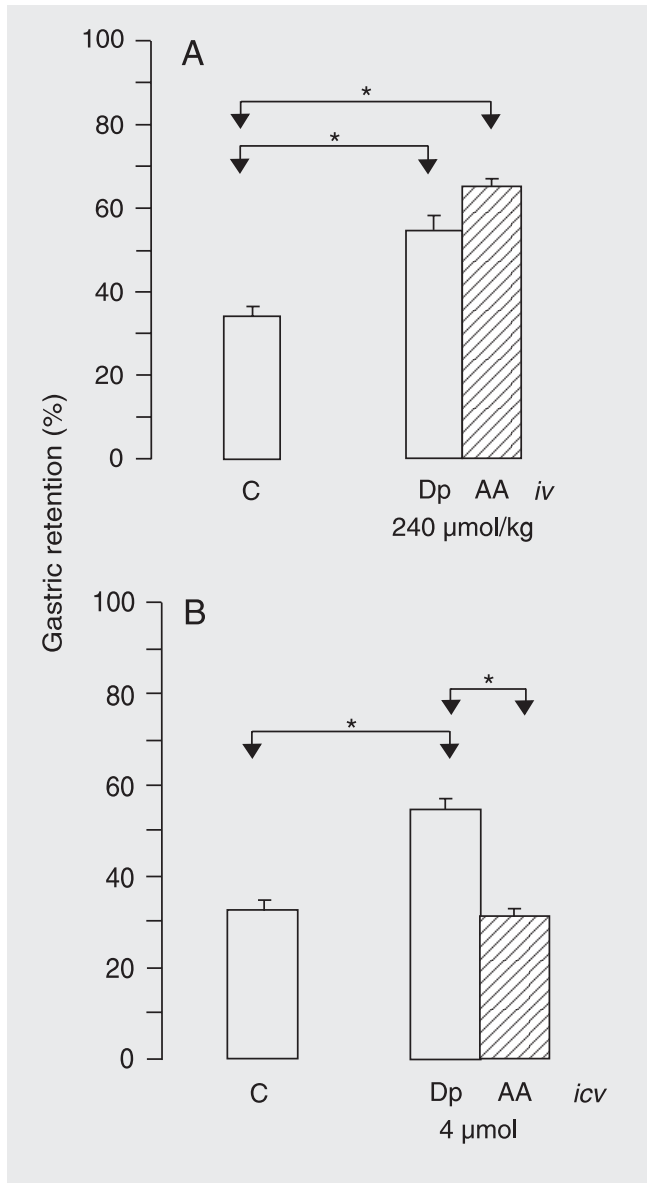

Figure 2. Volume-pressure curves after intragastric instillation of increasing saline volumes in anesthetized rats injected with dipyrone (Dp) iv or 4-aminoantipyrine (AA) at the dose of 240 $\mu \mathrm{mol} / \mathrm{kg}$ body weight or with vehicle (saline). Data are reported as mean $\pm \mathrm{SEM}$; $\mathrm{Dp}(\mathrm{N}=11)$, AA $(N=10)$, saline $(N=10)$; ${ }^{*} P$ $<0.05$ compared to the saline control (Tukey test). istration of AA.

Figure 2 presents the volume-pressure curves for the rats treated $i v$ with Dp and AA and for the saline controls. The pressures obtained with drug application in the three measurements were significantly lower than control. In addition, gastric compliance was significantly greater in the animals treated with Dp (mean \pm SEM, $0.26 \pm 0.009 \mathrm{~mL} /$ $\mathrm{mmHg}, \mathrm{N}=11)$ and AA $(0.24 \pm 0.012 \mathrm{~mL} /$ $\mathrm{mmHg}, \mathrm{N}=10$ ) compared to the saline control $(0.19 \pm 0.009 \mathrm{~mL} / \mathrm{mmHg}, \mathrm{N}=10)$. The two drugs did not differ from one another regarding the effects on the volumepressure curves and on gastric compliance.

There was a significant increase in GR in the animals treated $i v$ with AA at the doses of 60,120 , and $240 \mu \mathrm{mol} / \mathrm{kg}$ compared to control (Figure 3A), with a positive and significant correlation $(r=0.92)$. We also observed that, at the dose of $240 \mu \mathrm{mol} / \mathrm{kg}$, the GR of the saline test meal was marked and significant at 10, 30, and 60 min compared to the respective controls, with a reduction at 120 $\mathrm{min}$, and being no longer significant at 240 min (Figure 3B).

$\mathrm{VgX}$ reduced the effect of AA on GR, although a significant difference continued to be present compared to the animals submitted to the same surgical procedure and treated with vehicle (Figure 4A). There was a significant reduction of GR in $\mathrm{VgX}$ animals treated with AA compared to the sham group also treated with the drug $(\mathrm{VgX}+\mathrm{AA}$ $v s$ sham + AA) and nonsignificant reduction of GR between the control groups ( $\mathrm{VgX}+$ control vs sham + control). This reduction was more intense, about 2.5-fold, among the animals treated with AA (a $56 \%$ reduction of mean GR) than in the control groups (a $22.3 \%$ reduction of mean GR).

The results regarding the effect of the $i c v$ administration of bac on the effect of AA are illustrated in Figure 4B. The bac0 AA group had a significantly greater GR compared to the bac0 control group. On the other hand, the GR of the bac2 AA group did not differ 
significantly from control (bac2 control). Bac administered $i c v$ significantly reduced GR in the animals treated $i v$ with AA (bac0 AA $v s$ bac2 AA), as also observed in the control group treated with $i v$ saline (bac0 control vs bac2 control). However, the reduction was 2-fold greater among those treated with AA (a 56.4\% reduction of mean GR) than among those that received saline (a $24.5 \%$ reduction of mean GR).

\section{Discussion}

AA and Dp administered $i v$ at equimolar doses caused a similar delay of GE of the same test liquid meal (Figure 1A). AA is one of the Dp metabolites that reaches $60 \%$ of plasma concentration in the CNS after the administration of this pro-drug (13). In a previous paper (1), we demonstrated that $i c v$ Dp at a dose 16-fold higher than that administered $i v$ delays liquid GE, but this phenomenon was not observed with AA. These results were confirmed in the present study (Figure 1B).

Intravenous administration at equimolar doses of the two phenylpyrazolone derivatives to anesthetized animals induced an increase in gastric compliance nearly equal. Since gastric compliance reflects accommodation of the proximal stomach (fundus and part of the body), an area that is also responsible for GE of liquid (3), it is possible that the effect of these derivatives on GE or on part of it is the consequence of an increased relaxation of this functional part of the stomach.

The effect of AA on GE was dose dependent but was more intense and uniform during the first hour after administration (Figure $3 \mathrm{~A}$ and $\mathrm{B}$ ). In some aspects the results differed from those previously reported by us for $\mathrm{Dp}(1)$, i.e., at the dose of 60 $\mu \mathrm{mol} / \mathrm{kg}$ the effect of AA was significant compared to control, and 120 min after administration of the AA dose of $240 \mu \mathrm{mol} / \mathrm{kg}$ the difference from control was maintained even though there was a reduction of the effect of the drug.

There is evidence of vagus involvement in the delay of GE induced by AA since vagotomy reduced the effect of the drug, which was 2.5 -fold greater than that observed in the animals that did not receive the
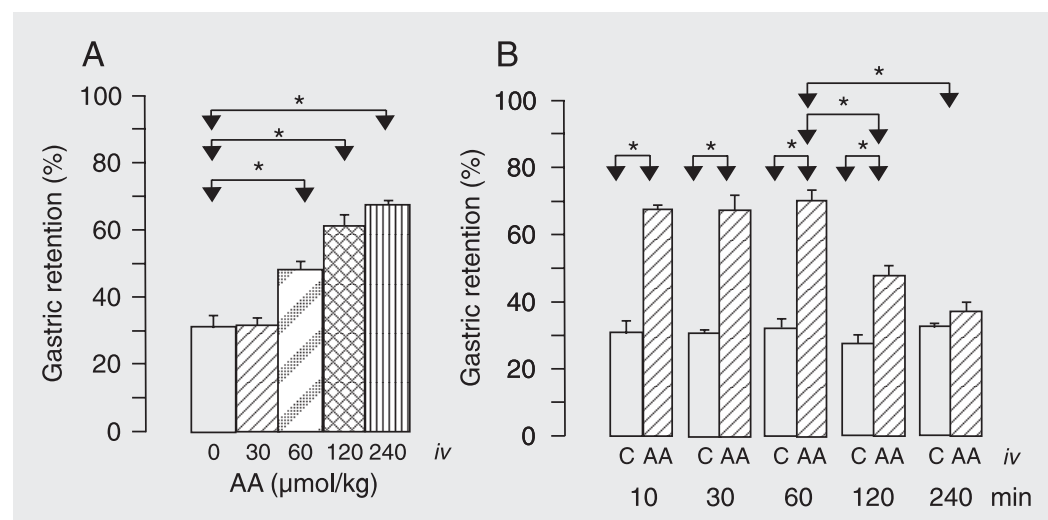

Figure 3. Gastric retention of a saline test meal $10 \mathrm{~min}$ after administration to rats by gavage. $A$, Ten minutes before the evaluation of gastric retention, the animals received vehicle (C) or 30, 60, 120, and $240 \mu \mathrm{mol} / \mathrm{kg}$ 4-aminoantipyrine (AA) iv. B, Ten, 30, 60, 120, and 240 min before the evaluation of gastric retention, the animals received vehicle $(C)$ or $240 \mu \mathrm{mol} / \mathrm{kg} \mathrm{AA} \mathrm{i}$. Data are reported as mean \pm SEM for 5 animals per group. ${ }^{*} \mathrm{P}<0.05$ compared to control (Tukey test).
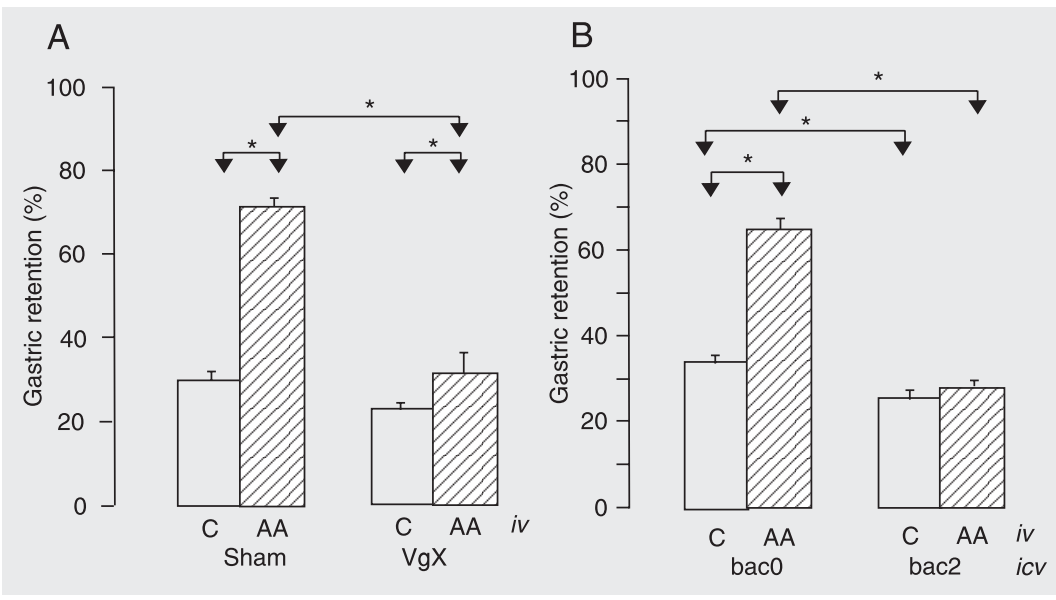

Figure 4. Gastric retention of a saline test meal $10 \mathrm{~min}$ after administration to rats by gavage. $A$, Two weeks before the experiment the animals were submitted to sham surgery or to subdiaphragmatic vagotomy $(\mathrm{VgX})$. Ten minutes before the evaluation of gastric retention, the rats in each group received vehicle (C) or 4-aminoantipyrine (AA), $240 \mu \mathrm{mol} /$ $\mathrm{kg}$ iv. B, A metal cannula was implanted into the right lateral ventricle of all rats 8 days before the experiment. The animals received an injection of $10 \mu \mathrm{L}$ vehicle (bac0) or an equal volume of a solution containing $2 \mu \mathrm{g}$ baclofen (bac2) icv injected over a period of $30 \mathrm{~s}$, and vehicle (C) or a solution of AA, $240 \mu \mathrm{mol} / \mathrm{kg}$ (AA, $48.77 \mathrm{mg} / \mathrm{kg}$ ) iv. Gastric retention was evaluated $10 \mathrm{~min}$ after the $i v$ injections. Data are reported as mean \pm SEM for 10 animals per group. ${ }^{*} \mathrm{P}<0.05$ compared to control (Tukey test). 
drug (Figure 4A). However, the difference continued to be significant compared to control. In a previous study, we observed that vagotomy fully abolished the effect of Dp (1). On this basis, it is not possible to exclude the apparently discrete action of AA, independent of the vagus nerve, on smooth muscle fibers and/or on the enteric nervous system of the stomach and duodenum, about which no information is available. The in vitro effect of Dp using preparations of intestinal segments (gastric musculature, jejunum and ileum) and of the ureter was minimal or absent (14-17).

Additionally, it was demonstrated that the delay in GE determined by AA was blocked by the administration of bac in the CNS (Figure 4B), as also reported for Dp (2). In the CNS, bac activates $\mathrm{GABA}_{\mathrm{B}}$ receptors, promoting modulation of neurotransmission by hyperpolarization of the postsynaptic membranes or inhibition of neurotransmitter release at the presynaptic endings (18). There is evidence that GABA participates in the control of gastric motility at the level of the nucleus tractus solitarii, a CNS structure that receives afferent information through the vagus nerve (19-21).

Although the mechanisms by which Dp and AA cause a delay in GE are unknown, it is possible to speculate that the phenomenon is due to the effect of a disequilibrium between the efferent stimulatory/inhibitory system of the vagus on gastric tonus, with origin in the CNS. Supporting this is the fact that vagotomy and the $i v$ activation of $\mathrm{GABA}_{\mathrm{B}}$ receptors reduced the delay in GE caused by Dp $(1,2)$ and by AA. Additionally, since AA had no effect when administered $i c v$, it is possible that the stimulation of the delay in GE produced by this metabolite reaches the CNS through an afferent pathway.

This hypothesis may be relevant also for antipyrine, another phenylpyrazolone derivative studied in our laboratory (22). In that study antipyrine showed some similarities to AA such as producing no effect when administered directly into the CNS and a reduced effect after vagotomy and after bac administration. However, antipyrine showed one difference compared to AA, i.e., the effect was more intense at $10 \mathrm{~min}$ after the administration of antipyrine, possibly due to the fact that the pharmacokinetics of antipyrine differs from that of AA (22).

On the other hand, it is reasonable to assume that the more prolonged effect of AA, which was not fully abolished by vagotomy, is due to the use of a higher $i v$ dose in relation to the amount of this metabolite, which would be generated slowly in the internal medium from Dp. On this basis, Dp administered $i v$ would produce a delay in GE not only through a possible direct action on the CNS (1), but also by the peripheral action of at least one of its metabolites (AA). This hypothesis, plus the possible participation of other metabolites, make it questionable that the $i v$ effect of Dp on GE would occur by a direct action on the CNS, as previously proposed (1), actually functioning as a pro-drug.

Our data suggest that AA and Dp administered $i v$ increase gastric compliance, and AA, with the participation of the vagus nerve, induces delayed GE of liquid in rats through a pathway that does not involve a direct action of the drug on the CNS.

\section{References}

1. Collares EF, Vinagre AM. Evidence of the effect of dipyrone on the central nervous system as a determinant of delayed gastric emptying observed in rats after its administration. Braz J Med Biol Res 2003; 36: 1375-1382.

2. Collares $E F$, Vinagre $A M$. Effect of the $G A B A_{B}$ agonist baclofen on dipyrone-induced delayed gastric emptying in rats. Braz J Med Biol Res 2005; 38: 99-104.

3. Weisbrodt NW. Gastric emptying. In: Johnson LR (Editor), Gastrointestinal physiology. 5th edn. St. Louis: Mosby; 1997. p 33-42.

4. Bustorff-Silva J, Perez CA, Fonkalsrud EW, Hoh C, Raybould HE. 
Gastric emptying after fundoplication is dependent on changes in gastric volume and compliance. J Pediatr Surg 1999; 34: 12321235.

5. Azpiroz F. Control of gastric emptying by gastric tone. Dig Dis Sci 1994; 39: 18S-19S.

6. Brogden RN. Pyrazolone derivatives. Drugs 1986; 32 (Suppl 4): 6070.

7. Levy M, Zylber-Katz E, Rosenkranz B. Clinical pharmacokinetics of dipyrone and its metabolites. Clin Pharmacokinet 1995; 28: 216234.

8. Kraul H, Pasanen M, Sigusch H, Stenback F, Park SS, Gelboin HV, et al. Immunohistochemical properties of dipyrone-induced cytochromes P450 in rats. Hum Exp Toxicol 1996; 15: 45-50.

9. Kato R, Takanaka A, Onoda KI, Omori Y. Drug affecting the gastric emptying rate and drug absorption. Jpn J Pharmacol 1972; 22: 434436.

10. Takanaka A, Onoda K, Kainuma E, Lienard F, Omori Y. Effect of phenylpyrazolone derivatives on gastric emptying rate and drug absorption in rats. Jpn J Pharmacol 1973; 23: 745-747.

11. Vinagre AM, Collares EF. Efeito da 4-aminoantipirina sobre o esvaziamento de ratos. XIX Annual Meeting of the Federação de Sociedades de Biologia Experimental. August 25-28; Águas de Lindóia, SP, Brazil. 2004. p 09.050 (Abstract).

12. Bucaretchi F, Collares EF. Effect of Phoneutria nigriventer spider venom on gastric emptying in rats. Braz J Med Biol Res 1996; 29: 205-211.

13. Cohen O, Zylber-Katz E, Caraco Y, Granit L, Levy M. Cerebrospinal fluid and plasma concentrations of dipyrone metabolites after a single oral dose of dipyrone. Eur J Clin Pharmacol 1998; 54: 549553.

14. Alexander $\mathrm{K}$, Khreis A, Traut $\mathrm{G}$. The combined effect of noramidopyrine-methanesulfonate with choline and acetylcholine. Arzneimittelforschung 1963; 13: 493-497.

15. Schiantarelli $\mathrm{P}$, Murmann W, Magi S. Investigation of rociverine + dipyrone for antispasmodic and analgesic interactions. Arzneimitte/forschung 1979; 29: 760-765.

16. Hertle L, Nawrath $\mathrm{H}$. Effect of Baralgin on isolated preparations of the upper urinary tract in man. Urol Int 1984; 39: 84-90.

17. Herbert MK, Weis R, Holzer P, Roewer N. Peristalsis in the Guinea pig small intestine in vitro is impaired by acetaminophen but not aspirin and dipyrone. Anesth Analg 2005; 100: 120-127.

18. Couve A, Moss SJ, Pangalos MN. GABA $A_{B}$ receptors: a new paradigm in G protein signaling. Mol Cell Neurosci 2000; 16: 296-312.

19. Sivarao DV, Krowicki ZK, Hornby PJ. Role of GABA $A$ receptors in rat hindbrain nuclei controlling gastric motor function. Neurogastroenterol Motil 1998; 10: 305-313.

20. Bertolino M, Kellar KJ, Vicini S, Gillis RA. Nicotinic receptor mediates spontaneous GABA release in the rat dorsal motor nucleus of the vagus. Neuroscience 1997; 79: 671-681.

21. Yuan CS, Liu D, Attele AS. GABAergic effects on nucleus tractus solitarius neurons receiving gastric vagal inputs. J Pharmacol Exp Ther 1998; 286: 736-741.

22. Soares AC, Vinagre AM, Collares EF. Effect of antipyrine on the gastric emptying of liquid in rats. Braz J Med Biol Res 2006; 39: 1507-1512. 